\title{
Novel hydrogel obtained by chitosan and dextrin-VA co-polymerization
}

\author{
Reinaldo Ramos $\cdot$ Vera Carvalho $\cdot$ Miguel Gama
}

Received: 22 February 2006/ Accepted: 24 April 2006/Published online: 27 June 2006

(C) Springer Science+Business Media B.V. 2006

\begin{abstract}
A novel hydrogel was obtained by reticulation of chitosan with dextrin enzymatically linked to vinyl acrylate (dextrin-VA), without cross-linking agents. The hydrogel had a solid-like behaviour with $\mathrm{G}^{\prime}$ (storage modulus) $>>G^{\prime \prime}$ (loss modulus). Glucose diffusion coefficients of $3.9 \times 10^{-6} \pm 1.3 \times 10^{-6} \mathrm{~cm}^{2} / \mathrm{s}$ and $2.9 \times 10^{-6} \pm 0.5 \times 10^{-6} \mathrm{~cm}^{2} / \mathrm{s}$ were obtained for different substitution degrees of the dextrin-VA (20\% and $70 \%$ respectively). SEM observation revealed a porous structure, with pores ranging from $50 \mu \mathrm{m}$ to $150 \mu \mathrm{m}$.
\end{abstract}

Keywords Chitosan Dextrin-VA ·

Diffusion coefficient · Hydrogel $\cdot$ Rheology

\section{Introduction}

Hydrogels are a class of three-dimensional, highly hydrated polymeric networks (Peppas et al. 2000). They are suitable for biomedical applications because of their high tissue compatibility mainly caused by the high water content of the gels (Drury and Mooney 2003). Hydrogels made of natural polymers are suitable for tissue engi-

R. Ramos · V. Carvalho · M. Gama $(\bowtie)$

Centro de Engenharia Biológica, Universidade do Minho, Campus de Gualtar, 4710-057 Braga, Portugal

e-mail: fmgama@deb.uminho.pt neering applications because they are components of, or have macromolecular properties similar to, the natural extracellular matrix (Montembault et al. 2005).

Chitosan (poly[ $\beta$-(1-4)-2-amino-2-deoxy-D-glucopyranose]) is a non-toxic and biocompatible co-polymer of $\mathrm{N}$-glucosamine and $\mathrm{N}$-acetyl-glucosamine produced by partial deacetylation of chitin. Chitosan is susceptible to structural modifications due to the high number of hydroxyl and amine reactive groups. It has been extensively studied for applications in areas as diverse as wastewater treatment (flocculating properties, chelation and ion exchange properties), cosmetic (hair and skin care), paper and textiles (conditioning polymer), biomedicine and biology (drug delivery, enzyme immobilization, orthopaedic/ periodontal, tissue engineering and wound healing), and agro-industries (seed treatment) (Jaworska et al. 2003).

Dextrin is a glucose-containing polysaccharide linked by $\alpha-(1 \rightarrow 4)$ D-glucose units, with the same general formula as starch, although it is smaller and less complex. This polysaccharide is produced by partial hydrolysis of starch, which can be accomplished by the use of acids and/or enzymes (J.M. Carvalho, C. Gonçalves, A.M. Gil, F.M Gama, submitted).

In the present work, we describe the development of a novel hydrogel obtained by polymerization of chitosan with dextrin-VA. 


\section{Materials and methods}

\section{Materials}

$\mathrm{D}_{2} \mathrm{O}$, chitosan and chitin from crab shells were obtained from Sigma. Proleather FG-F, protease was obtained from Amano Enzyme Co. Dextrin Koldex 60 starch was a generous gift from Tate \& Lyle. Vinyl acrylate (VA) was from Aldrich, dimethylsulfoxide (DMSO) and acetone were from AppliChem. (Germany).

DMSO was dried with $0.4 \mathrm{~nm}$ molecular sieves overnight before use. Regenerated cellulose tubular membranes with $3500 \mathrm{MWCO}$ were obtained from Membrane Filtration Products.

Enzymatic synthesis of dextrin-VA

The enzyme-catalyzed modification of dextrin, with various degrees of substitution (DS) was as described elsewhere (J.M. Carvalho, C. Gonçalves, A.M. Gil, F.M Gama, submitted). DS is defined as the number of acrylate groups per 100 glucopyranose residues. Briefly, dextrin $(4 \mathrm{~g})$ and two volumes of VA ( $650 \mu \mathrm{l}$ gave a DS of $20 \%$ and $2.6 \mathrm{ml}$ a DS of $70 \%$ ) were dissolved in anhydrous DMSO $(60 \mathrm{ml})$.

The reaction was initiated by adding $600 \mathrm{mg}$ of Proleather FG-F. The reaction mixture was then incubated at $50^{\circ} \mathrm{C}$ with magnetic stirring for $72 \mathrm{~h}$. Figure 1, reaction A, (see below) shows the chemical reaction of dextrin activation. The mixtures were then dialyzed for 5 days against deionized water, $\mathrm{pH} 3$ (adjusted with $6 \mathrm{M} \mathrm{HCl}$ ), at $4^{\circ} \mathrm{C}$. The aqueous solutions of dextrin-VA were evaporated and freeze-dried.

The degree of substitution was determined by ${ }^{1} \mathrm{H}$ NMR according to Ferreira et al. (2002). Briefly, ${ }^{1} \mathrm{H}$ NMR spectra were recorded in $\mathrm{D}_{2} \mathrm{O}$ (10 $\mathrm{mg}$ in $1 \mathrm{ml}$ ) and DS was calculated using Eq. (1):

$\mathrm{DS} \%=\frac{x}{y} \times \frac{7}{3} \times 100$

where, in the NMR spectra, $x$ is the sum of the peak intensities corresponding to the protons from vinyl group ( $\delta$ in the range of $6.44-6.00 \mathrm{ppm}$ ) and $y$ is the sum of the peak intensities of all dextran protons $(\delta$ in the range of 5.50-3.10 ppm).

\section{Preparation of chitosan-dextrin-VA hydrogels}

Chitosan-dextrin-VA hydrogels were obtained after reticulation of chitosan with dextrin-VA. Chitosan was dissolved in $0.1 \mathrm{M}$ acetic acid. The $\mathrm{pH}$ was raised to 6 so that a higher number of reactive amines $\left(\mathrm{NH}_{2}\right)$ were available. The chitosan solution was mixed with various quantities of solid dextrin-VA and transferred to a casting mould. The polymerization occurred at room temperature for $24 \mathrm{~h}$.

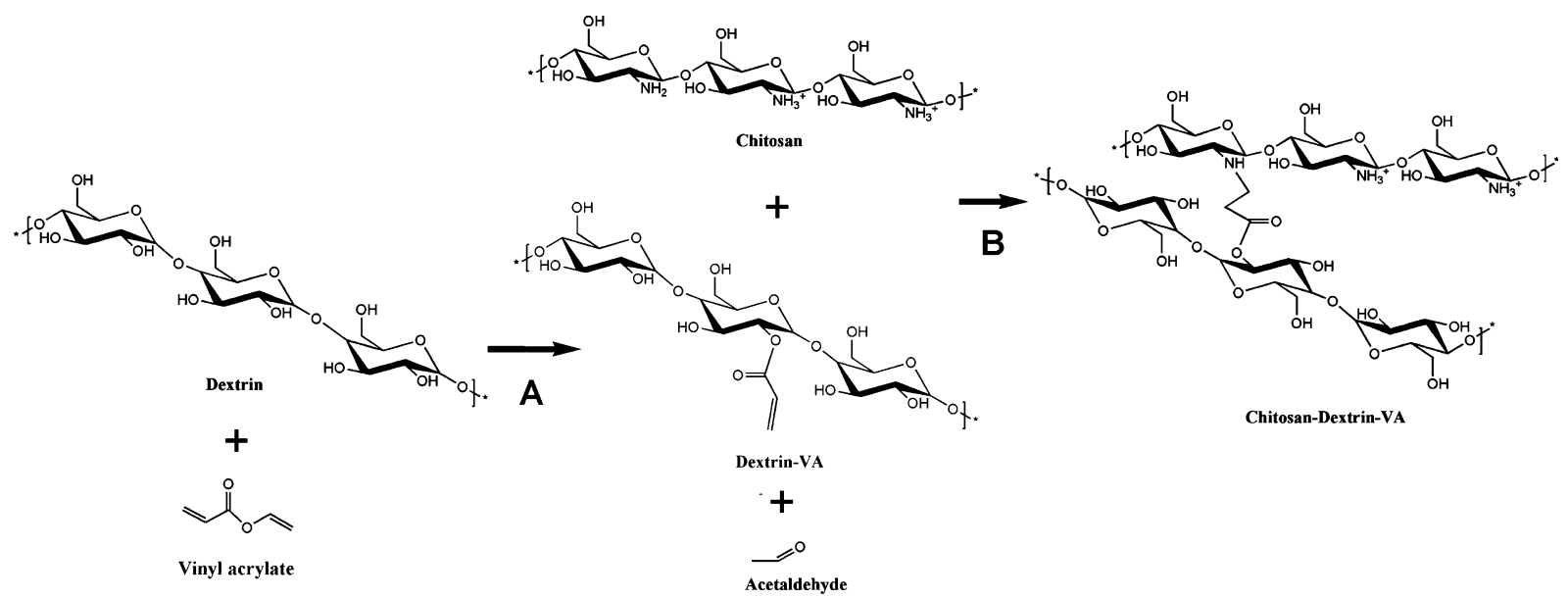

Fig. 1 (A) Reaction between dextrin and vinyl acrylate forming dextrin-VA and acetaldehyde. (B) Reaction between chitosan and dextrin-VA leading to hydrogel formation 
Rheology

Rheological experiments were performed at $25^{\circ} \mathrm{C}$ to characterize the mechanical behaviour of the hydrogels. The intrinsic mechanical properties of the gel network are determined submitting the material to compression and decompression cycles. Rheological analyses of the hydrated hydrogels, with different concentrations of dextrin-VA, (25 mm diam. disk, $2 \mathrm{~mm}$ thick) were carried out using a Reologica StressTech HR reometer in parallel-plate geometry, with a variable gap. Smallamplitude oscillatory shear measurements were recorded with gaps varying from $0.8 \mathrm{~mm}$ to $1.8 \mathrm{~mm}$ to determine the variation of storage and loss module ( $G^{\prime}$ and $G^{\prime \prime}$ respectively), with frequencies ranging from $0.01 \mathrm{~Hz}$ to $100 \mathrm{~Hz}$ under various compression levels. The linear viscosity region was determined by stress sweep measurements to determine at which values the gel structure remained constant.

\section{Diffusivity}

Diffusion coefficients of glucose in the chitosandextrin-VA hydrogels were calculated. The diffusion cell is a modification of Teixeira et al. (1994). It is made of Perspex and consists of two chambers of $60 \mathrm{ml}$, divided by a Perspex plate, and held together with screws. The hydrogel (diameter $20 \mathrm{~mm}$; thickness of $0.5 \mathrm{~mm}$ ) was inserted in the Perspex plate. The Perspex plate was supported by a squared mesh and sealed with O-rings. Agitation was obtained using magnetically driven bars in both chambers.

Samples were collected in the upper chamber through a port, and the soluble sugars were determined using the dinitrosalicylic acid method. Concentration of glucose in the lower chamber was $100 \mathrm{~g} / 1$.

The diffusion coefficients were calculated using lag-time analysis (Teixeira et al. 1994):

$Q_{t s}=\frac{A D C_{1}}{l}\left(t_{s}-\frac{l^{2}}{6 D}\right)$

where $Q$ is the total amount of solute transferred through the membrane, $A$ the area, $D$ the diffusion coefficient, $C$ the concentration, $l$ the membrane thickness and $t$ the time.

The intercept of the linear part of the curve obtained by plotting $Q$ versus time is the lag time.

The diffusion coefficients were calculated from the lag time and the membrane thickness.

Diffusion coefficients of glucose were determined for hydrogels with a dextrin-VA concentration of $60 \mathrm{mg} / \mathrm{ml}$.

\section{SEM analysis}

The hydrogels were first frozen at $-20^{\circ} \mathrm{C}$ and lyophilized. The samples were coated with gold particles in a Fisons Instruments Polaron SC502 Sputter Coater and observed by electron microscopy (Leica, Cambridge S360).

\section{Results and discussion}

\section{Chitosan-dextrin-VA Hydrogels}

The chitosan-dextrin-VA hydrogels were obtained upon reticulation of chitosan with dextrin-VA. The amine group reacts with the acrylate group of dextrin-VA (Fig. 1, reaction B), according to a conjugate 1, 4 addition mechanism. In this reaction, the nucleophile (amine group) reacts with the $\mathrm{C}=\mathrm{C}$ double bond of the $\alpha, \beta$ unsaturated acrylate group.

Since only neutral amines of chitosan are reactive, the $\mathrm{pH}$ was carefully adjusted in order to have soluble chitosan with a significant fraction of amine groups in the neutral form. The $\mathrm{p} K_{\mathrm{a}}$ of chitosan is approximately 6.5 , which means that at this $\mathrm{pH}$, $50 \%$ of the amine groups are available to react. Adjusting the $\mathrm{pH}$ of the chitosan solutions is relatively slow, due to its high viscosity. It was possible to increase the $\mathrm{pH}$ to 6.3 , while keeping the polymer soluble, with chitosan at $1.5 \%$ (w/v). After reaching the desired $\mathrm{pH}$, the dextrin-VA was added to the chitosan solution, and the mixture was allowed to react for $24 \mathrm{~h}$ at room temperature.

The $\mathrm{pH}$ of the reaction medium strongly affects the polymerization kinetics (Fig. 2).

When the chitosan solution had a $\mathrm{pH}$ of 4.7, (flask A, Fig. 2), the mixture did not gel after 

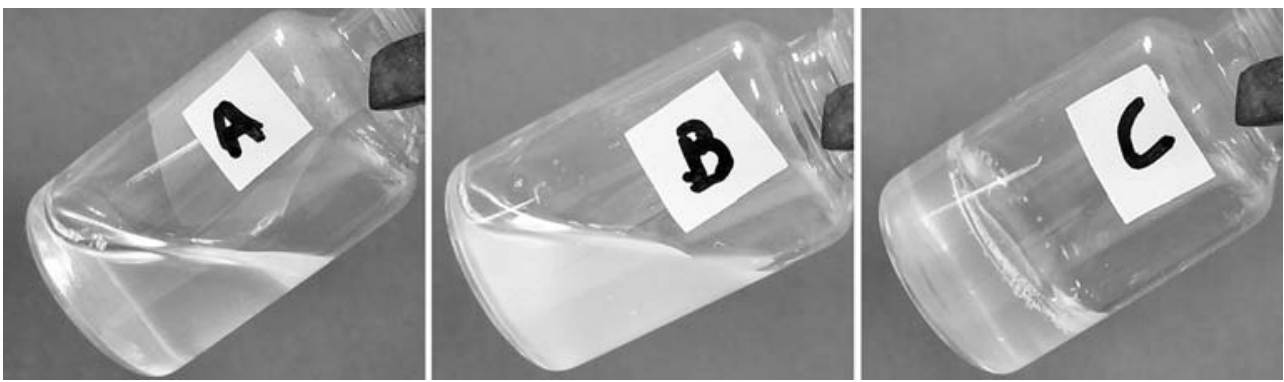

Fig. 2 Effect of the reaction medium pH (A vs. C) and of the dextrin substitution with vinyl acrylate (B vs. $\mathbf{C}$ ) on the gelification. (A) $3 \mathrm{ml}$ chitosan $\mathrm{pH} 4.7+30 \mathrm{mg}$ dextrin-

$24 \mathrm{~h}$. This may due to the low number of neutral amines at this $\mathrm{pH}$. The consistency of the hydrogel was very low, as compared to the one obtained at higher $\mathrm{pH}$ (flask C, Fig. 2). However, after 3 days, the hydrogel became more consistent and similar to the one obtained at $\mathrm{pH} 6.0$ after $24 \mathrm{~h}$. The reaction was slower due to the lower concentration of $\mathrm{NH}_{2}$, but as the reaction proceeded $\mathrm{NH}_{3}^{+}$dissociated, and more $\mathrm{NH}_{2}$ was available to react with the dextrin-VA. Nevertheless, the process was very slow. Figure 2 (B vs. C) showed also that chitosan reacted with dextrin-VA, but not with dextrin without linked VA. The results confirmed the reaction mechanism suggested in Fig. 1.

\section{Rheology}

Figure $3 \mathrm{~A}$ demonstrates the dynamic moduli $\mathrm{G}^{\prime}$ (storage modulus) and $\mathrm{G}^{\prime \prime}$ (loss modulus) of the different hydrogels. The gels displayed a solidlike behaviour, $G^{\prime}>G^{\prime \prime}$. Figure $3 B$ shows the

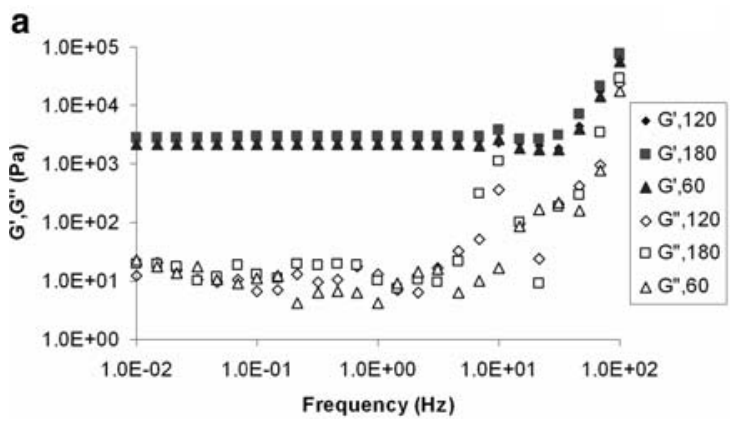

Fig. 3 The rheological experiments were performed with gels obtained using three different concentrations of dextrin-VA (60, 120 and $180 \mathrm{mg} / \mathrm{ml})$; (A) Dynamic moduli
VA; (B) 3 ml chitosan pH $6+30 \mathrm{mg}$ dextrin; (C) $3 \mathrm{ml}$ chitosan $\mathrm{pH} 6+30 \mathrm{mg}$ dextrin-VA

viscoelastic material functions $\mathrm{G}^{*}$ and $\eta$. Below $10 \mathrm{~Hz}, \eta$ varied linearly with a negative slope while $\mathrm{G}^{*}$ remained constant. No significant differences were observed for the different hydrogels. In fact, the different concentration of dextrin-VA did not affect the rheological properties of the hydrogels. $\mathrm{G}^{\prime}$ and $\mathrm{G}^{*}$ of ca. $5 \times 10^{3} \mathrm{~Pa}$ were obtained. These values are relatively high, as compared to those for poly[ $\mathrm{N}$ (2-hydroxypropyl)methacrylamide] (PHPMA) and hyaluronic acid hydrogels $\left(1 \times 10^{2}\right.$ and $5 \times 10^{2} \mathrm{~Pa}$, respectively) (Hou et al. 2005; Woerly et al. 2001 respectively). $\mathrm{G}^{*}$ and $\eta$ functions are similar to values determined for brain tissue: a constant $\mathrm{G}^{*}$ and $\eta$ that increased with decreasing frequency (Woerly et al. 2001).

\section{Diffusivity}

Dextrin-VA with two DS were used. Diffusion coefficients of $3.9 \times 10^{-6} \pm 1.3 \times 10^{-6} \mathrm{~cm}^{2} / \mathrm{s}$ and $2.9 \times 10^{-6} \pm 0.5 \times 10^{-6} \mathrm{~cm}^{2} / \mathrm{s}$, for the hydrogels

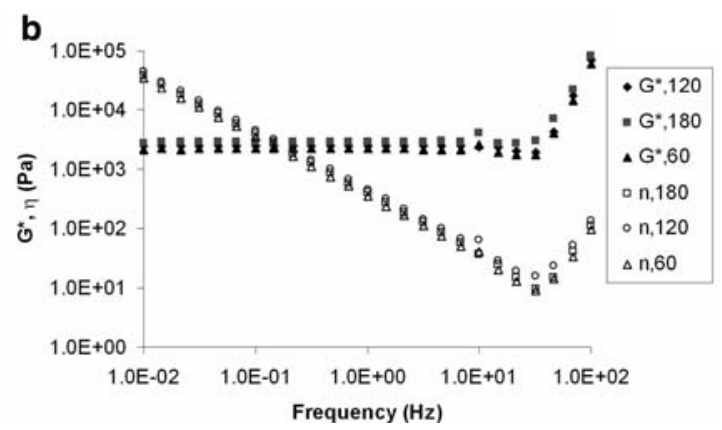

$\mathrm{G}^{\prime}$ and $\mathrm{G}^{\prime \prime}$, as function of the frequency. (B) Complex shear modulus $\mathrm{G}^{*}$ and viscosity $\eta$ 


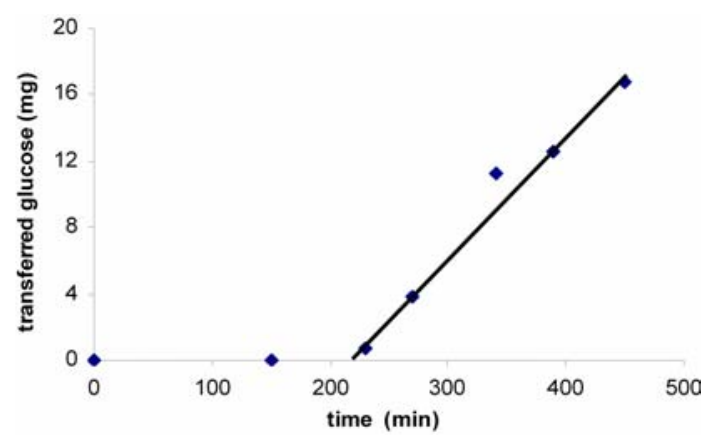

Fig. 4 Amount of glucose transferred through the hydrogel in the diffusion cell be suitable for three-dimensional neural tissue culture because of its positive charge.

\section{Conclusion}

A novel hydrogel was obtained upon polymerization of chitosan and dextrin-VA without initiators. These hydrogels are simple to produce and present interconnected micro and macropores. By varying the proportion of chitosan to dextrin-VA, and the dextrin-VA degree of substitution,

Fig. 5 SEM micrographs of Dextrin-VA-CS hydrogels with $200 \times$ magnification. (A) $120 \mathrm{mg}$ dextrin-VA/ml CS; (B) $180 \mathrm{mg}$ dextrin-VA/ml CS. Bar $=200 \mu \mathrm{m}$
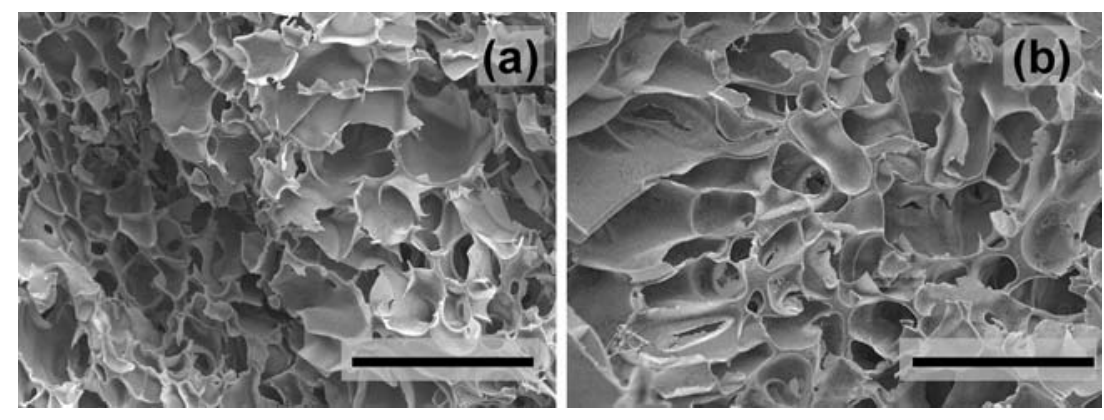

with a DS of 20 and $70 \%$ respectively, were obtained, using the lag-time analysis, as illustrated in Fig. 4. The results were calculated from four independent assays. The diffusion coefficient was slightly lower when using a higher substitution degree due to the higher number of acrylate groups. More reactive groups were available to react with chitosan and a more stable and reticulated hydrogel was obtained, exhibiting a lower glucose diffusion coefficient. The results were in the range of the ones obtained by Teixeira et al. (1994) for the diffusion of glucose in alginate membranes.

\section{SEM analysis}

Figure 5 provide images of the hydrogel obtained by electron microscopy at $200 \times$ magnification. The hydrogel presents irregular pores ranging from $50 \mu \mathrm{m}$ to $150 \mu \mathrm{m}$, with the smaller range being in the majority. This porous structure may be convenient for cell culture. In fact, the hydrogel may hydrogels with different properties (charge, porosity, strength) can be obtained. Further studies, such as swelling experiments and biocompatibility assays, will be performed to better characterize this new hydrogel, and assess its potential for biomedical applications, such as tissue engineering and drug delivery.

\section{References}

Drury JL, Mooney DJ (2003) Hydrogels for tissue engineering: scaffold design variables and applications. Biomaterials 24: 4337-4351

Ferreira L, Carvalho R, Gil MH, Dordick JS (2002) Enzymatic synthesis of dextran-containing hydrogels. Biomaterials 23: 3957-3967

Jaworska M, Kula K, Chassary P, Guibal E (2003) Influence of chitosan characteristics on polymer properties. I: crystallographic properties. Polym Int 52: 198205

Montembault A, Viton C, Domard A (2005) Rheometric study of the gelation of chitosan in a hydroalcoholic medium. Biomaterials 14:1633-1643

Peppas NA, Bures P, Leobandung W, Ichikawa H (2000) Hydrogels in pharmaceutical formulations. Eur J Pharm Biopharm 50: 27-46 
Hou S, Xu Q, Tian W, Cui F, Cai Q, Ma J, Lee I-S (2005) The repair of brain lesion by implantation of hyaluronic acid hydrogels modified with laminin. J Neurosci Meth 148: 60-70

Teixeira JA, Mota M, Venâncio A (1994) Model identification and diffusion coefficients determination of glucose and malic acid in calcium alginate membranes. Chem Eng J 56: B9-B14

Woerly S, Pinet L, de Robertis L, Van Diep D, Bousmina M (2001) Spinal cord repair with PHPMA hydrogel containing RGD peptides (NeuroGel ${ }^{\mathrm{TM}}$ ). Biomaterials 22: 1095-1111 